\title{
Bortezomib as a probable cause of the syndrome of inappropriate antidiuretic hormone secretion: A case report and review of the literature
}

\author{
CHENG-LAN LV and JUAN LI \\ Department of Hematology, The Affiliated Drum Tower Hospital of Nanjing \\ University Medical School, Nanjing, Jiangsu 210008, P.R. China
}

Received March 13, 2017; Accepted June 2, 2017

DOI: $10.3892 / \mathrm{mco} .2017 .1366$

\begin{abstract}
Bortezomib is a proteasome inhibitor that has been widely adopted for the treatment of hematological malignancies, including multiple myeloma and lymphoma, and has been considered significantly more tolerable compared with traditional chemotherapeutic drugs. Bortezomib has some potential side effects that involve a number of systems, including the gastrointestinal, hematological, nervous and musculoskeletal systems; however, involvement of the endocrine system is rare. We herein report the case of a patient treated for multiple myeloma who developed the syndrome of inappropriate antidiuretic hormone secretion after bortezomib was added to his chemotherapy regimen. Following treatment with an infusion of hypertonic saline and fluid restriction for $>2$ months, the serum sodium level gradually recovered.
\end{abstract}

\section{Introduction}

Bortezomib is a proteasome inhibitor that has demonstrated therapeutic efficacy for patients with progressive multiple myeloma, with the benefit of a milder toxicity profile compared with traditional chemotherapies. However, the side effects of bortezomib may affect a number of systems, including the gastrointestinal, hematological, nervous and musculoskeletal systems and, infrequently, the endocrine system (1-8).

The syndrome of inappropriate antidiuretic hormone secretion (SIADH) was first described in 1957 (9), and is an important cause of hyponatremia. SIADH may be idiopathic or secondary to numerous causes, including various drugs, malignancies, central nervous system disorders and pulmonary

Correspondence to: Professor Juan Li, Department of Hematology, The Affiliated Drum Tower Hospital of Nanjing University Medical School, 321 Zhongshan Road, Nanjing, Jiangsu 210008, P.R. China E-mail: juanli2003@163.com

Key words: bortezomib, multiple myeloma, syndrome of inappropriate antidiuretic hormone secretion abnormalities (Table I). The diagnosis of SIADH is made based on the assessment of clinical criteria (Fig. 1) (10).

\section{Case report}

A 44-year-old male patient with a 3-month history of multiple myeloma and no other previous medical history was prescribed a chemotherapy regimen of bortezomib and dexamethasone: Bortezomib $\left(1.3 \mathrm{mg} / \mathrm{m}^{2}\right)$ was administered on days $1,4,8$ and 11 of a 28 -day cycle, with dexamethasone (40 mg) administered IV on days 1-4. After 3 cycles of chemotherapy, the patient presented to the Affiliated Drum Tower Hospital of Nanjing University Medical School (Nanjing, China) in July 2015, complaining of fatigue and numbness of the distal extremities 6 days after his last chemotherapy administration. There had been no recent changes to his diet or water intake, and he had not used diuretic agents during the month prior to presentation.

Upon physical examination, the body temperature, blood pressure, heart rate and respiratory rate were normal. Auscultation of the heart and lungs was normal. There were no signs of edema, ascites, or dry mucous membranes. The patient had mild hypesthesia and muscle weakness (<grade 5) of the extremities.

Serum electrolyte assessment revealed a mild decrease in serum sodium concentration $(133.6 \mathrm{mmol} / \mathrm{l})$. Despite treatment with oral hypertonic saline, the patient's symptoms progressed. Two days later, the patient's serum sodium level was $121.6 \mathrm{mmol} / \mathrm{l}$. Blood analysis revealed that the patient's low serum sodium was accompanied by low plasma osmolality $(248 \mathrm{mOsm} / \mathrm{kg})$, low creatinine $(74 \mu \mathrm{mol} / \mathrm{l})$, low blood urea nitrogen $(2.1 \mathrm{mmol} / \mathrm{l})$, and low uric acid $(134 \mu \mathrm{mol} / \mathrm{l})$. Additionally, the urinary osmolality was high at $443 \mathrm{mOsm} / \mathrm{kg}$, and urinary sodium was high at $147.7 \mathrm{mmol} / \mathrm{l}$. The patient's potassium, calcium, phosphate, glucose, white blood cell count, hemoglobin, platelet, lactate dehydrogenase, total protein and triglycerides were all within the normal range throughout the duration of the clinical assessment. In addition, the patient's thyroid and adrenal function were evaluated and found to be normal (Table II). The patient had neither clinical signs of contraction nor expansion of the extracellular fluid and no diuretic agents had been used prior 
Table I. Causes of SIADH.

\begin{tabular}{|c|c|c|c|c|}
\hline Malignancies & CNS disorders & Drugs & Pulmonary disorders & Other causes \\
\hline Bronchogenic & Tumors & Tricyclic & Tuberculosis & NSIAD (hereditary) \\
\hline carcinoma & Subdural & antidepressants & Pneumonia & AIDS and ARC \\
\hline Oat cell carcinoma & Hematoma & Carbamazepine & Lung abscess & Prolonged strenuous \\
\hline Thymoma & Brain abscesses & Valproate & Bronchiectasis & Exercise \\
\hline Nasopharyngeal & Encephalitis & Oxycarbamazepine & Acute & Prolonged nausea and \\
\hline carcinoma & Meningitis & Clofibrate & respiratory & vomiting \\
\hline Pancreatic carcinoma & Systemic lupus & Ciprofloxacin & failure & Senile atrophy \\
\hline Stomach carcinoma & erythematous & Ethionamide & COPD & Idiopathic (elderly) \\
\hline Duodenum carcinoma & Acute intermittent & Amiodarone & Asthma & Urinary retention \\
\hline Ewing's sarcoma & porphyria & SSRI & Cystic fibrosis & Hypothyroidism \\
\hline Mesothelioma & Multiple sclerosis & Omeprazole & Positive & Hypocorticism \\
\hline Bladder carcinoma & Guillain-Barré & AVP analogues & pressure & Strongyloidiasis \\
\hline Ureteral/prostate & syndrome & Oxytocin & ventilation & \\
\hline carcinoma & Spinal cord & Narcotics & & \\
\hline Uterine/cervical & lesions & Chlorpropamide & & \\
\hline carcinoma & Cerebrovascular & Vincristine & & \\
\hline Olfactory & accident & Vinblastine & & \\
\hline neuroblastoma & Subarachnoid & Vinorelbine & & \\
\hline Leukemia & hemorrhage & Ifosfamide & & \\
\hline Lymphoma & Head trauma & Cyclophosphamide & & \\
\hline \multirow[t]{10}{*}{ Macroglobulinemia } & Acute psychosis & Nicotine & & \\
\hline & Delirium tremens & Antipsychotic & & \\
\hline & $\begin{array}{l}\text { Pituitary stalk } \\
\text { section }\end{array}$ & drugs & & \\
\hline & Trans-sphenoidal & ACE inhibitors & & \\
\hline & adenomectomy & Mirtazapine & & \\
\hline & Hydrocephalus & Amiodarone & & \\
\hline & Antiphospholipid & Ciprofloxacin & & \\
\hline & syndrome & Venlafaxine & & \\
\hline & Shy-Drager & Lamotrigine & & \\
\hline & syndrome & Fluoxetine & & \\
\hline
\end{tabular}

SIADH, syndrome of inappropriate antidiuretic hormone secretion; CNS, central nervous system; SSRI, selective serotonin-reuptake inhibitor; AVP, arginine vasopressin; ACE, angiotensin-converting enzyme; COPD, chronic obstructive pulmonary disease; NSIAD, nephrogenic syndrome of inappropriate antidiuresis; AIDS, acquired immune deficiency syndrome; ARC, AIDS-related complex.

to the development of hyponatremia. Taking into consideration the patient's laboratory values, the diagnostic criteria were met to make a diagnosis of hyponatremia due to SIADH (Fig. 1) (10).

When investigating the etiology of the patient's SIADH, reasons secondary to central nervous system disorders and pulmonary abnormalities were excluded through analyzing the patient's medical history, physical examination, and recent laboratory and radiological tests. Idiopathic reasons, listed in Table I, did not fit the clinical profile of the patient. Certain malignancies, such as bronchogenic carcinoma, thymoma, lymphoma and macroglobulinemia, may also cause SIADH. The patient had high serum immunoglobulin A levels during the early stages of multiple myeloma, but the high level of serum immunoglobulin A normalized after two cycles of chemotherapy. At the time of presentation for SIADH, the patient had already achieved complete remission (CR) from his multiple myeloma, as determined through evaluation of the patient's blood and bone marrow. This decreased the likelihood that SIADH was directly associated with his diagnosis of multiple myeloma and disease progression. By process of elimination, the most likely cause was SIADH secondary to medications. Dexamethasone is unlikely to cause SIADH, based on its mechanism of action and pharmacokinetics, and has never been reported. Bortezomib was suspected as the offending agent, given its recent introduction into the patient's regimen and its documented risk (0.1-1\%) of causing endocrine disorders, such as SIADH (2).

The patient was treated with an infusion of hypertonic saline and fluid restriction. Despite appropriate treatment, his serum sodium level decreased further, reaching a nadir of $114.9 \mathrm{mmol} / \mathrm{l}$. However, the serum sodium level eventually 


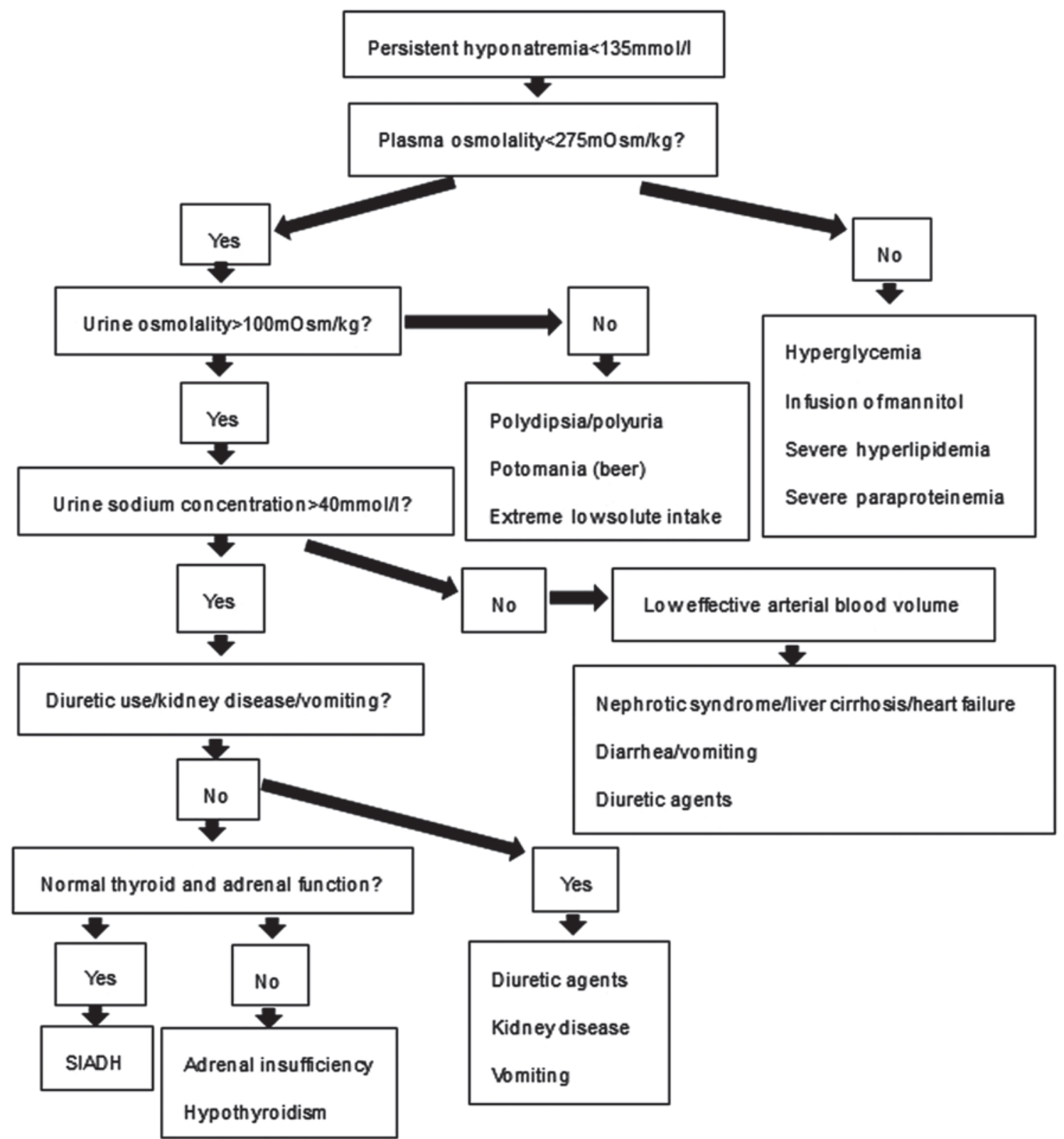

Figure 1. The diagnostic process of syndrome of inappropriate antidiuretic hormone secretion (SIADH).

started to normalize and, when it had reached $128.9 \mathrm{mmol} / 1$, the patient experienced an improvement of his fatigue and numbness in the distal extremities, and he asked to be discharged from the hospital against advice from the treating physicians, who recommended continued hospitalization for longer treatment. The patient was followed up with outpatient tests and fluid restriction, but discontinued the infusion of hypertonic saline. At 78 days after initially presenting with hyponatremia, the patient's serum sodium level had normalized (135 mmol/l) and his symptoms had disappeared (Fig. 2). Fluid restriction was discontinued, and the serum sodium levels remained normal. Bortezomib was not added to the next chemotherapy cycle. The patient subsequently received melphalan, prednisone and thalidomide for one course, after which time treatment for multiple myeloma was discontinued. The patient maintained CR on the last follow-up in February 2017, and the sodium levels remained normal.

\section{Discussion}

We herein report a case of SIADH suspected to be secondary to bortezomib treatment. A diagnosis of SIADH was made according to the diagnostic clinical criteria (Fig. 1) (10). SIADH is a common cause of hyponatremia, and it is associated with significant morbidity and mortality (11), longer hospitalization (12), osteoporosis (13), falls and fractures $(13,14)$. SIADH may be idiopathic or secondary to numerous drugs, malignancies, central nervous system disorders, or pulmonary abnormalities (Table I). Due to this patient's recent history of malignancy, tumor-related SIADH was considered as a possibility. However, to the best of our knowledge, multiple myeloma has never been associated with SIADH to date. Additionally, the patient in this case study had successfully achieved CR after chemotherapy; hence, a direct malignancy-related cause was unlikely. After ruling out other 
Table II. Laboratory values of the patient.

\begin{tabular}{|c|c|c|}
\hline Laboratory mesurements & Results & Normal range \\
\hline Blood pressure (mmHg) & $105 / 60$ & $100-130 / 60-80$ \\
\hline Blood glucose (mmol/l) & 5.15 & $3.9-6.1$ \\
\hline Serum $[\mathrm{Na}+](\mathrm{mmol} / \mathrm{l})$ & 121.6 & $135-145$ \\
\hline Serum chloride (mmol/l) & 82 & 98-108 \\
\hline Serum calcium (mmol/l) & 2.32 & $2.25-2.75$ \\
\hline Serum phosphate (mmol/l) & 0.91 & $0.96-1.62$ \\
\hline White blood cell (x109/1) & 9.5 & 4-10 \\
\hline Blood platelet count $\left(\mathrm{x} 10^{9} / 1\right)$ & 105 & $100-300$ \\
\hline Hemoglobin $(\mathrm{g} / \mathrm{l})$ & 130 & $130-172$ \\
\hline Hematocrit (proportion of 1.0) & 0.4 & $0.38-0.508$ \\
\hline Serum LDH (U/l) & 380 & $109-245$ \\
\hline Serum urea nitrogen $(\mathrm{mmol} / \mathrm{l})$ & 2.1 & $2.9-7.5$ \\
\hline Serum creatinine $(\mu \mathrm{mol} / \mathrm{l})$ & 74 & 44-106 \\
\hline Serum uric acid $(\mu \mathrm{mol} / \mathrm{l})$ & 134 & $90-420$ \\
\hline Serum $[\mathrm{K}+](\mathrm{mmol} / \mathrm{l})$ & 4.22 & $3.5-5.5$ \\
\hline Serum total protein $(\mathrm{g} / \mathrm{l})$ & 65.5 & $62-85$ \\
\hline Serum Albumin $(\mathrm{g} / \mathrm{l})$ & 41.2 & $35-51$ \\
\hline Serum triglycerides $(\mathrm{mmol} / \mathrm{l})$ & 2.5 & $0.56-1.7$ \\
\hline Serum cholesterol (mmol/l) & 4.62 & $2.9-6$ \\
\hline Serum cortisol (nmol/l) & 574 (08:00)-414 (16:00) & $138-690(08: 00) / 69-345(16: 00)$ \\
\hline Serum ACTH (pmol/l) & $2.51(08: 00)-1.59(16: 00)$ & $0-10.13$ \\
\hline Serum urine specific gravity & 1.005 & $1.003-1.030$ \\
\hline $\mathrm{TSH}(\mathrm{mIU} / \mathrm{l})$ & 5.98 & $0.27-4.2$ \\
\hline Free T4 (pmol/l) & 20.58 & $12-22$ \\
\hline Anti-thyroglobulin antibody $(\mathrm{U} / \mathrm{ml})$ & 17.8 & $0-115$ \\
\hline Antimicrosomal antibody(U/ml) & 18.18 & $0-34$ \\
\hline Urinary $\mathrm{K}^{+}(\mathrm{mmol} / 24 \mathrm{~h})$ & 32.15 & $25-125$ \\
\hline Urinary $\mathrm{Na}^{+}(\mathrm{mmol} / \mathrm{l})$ & 147.7 & $<20-30$ \\
\hline Plasma osmolality (mOsm/kg) & 248 & $275-305$ \\
\hline Urine osmolality (mOsm/kg) & 443 & $300-1000$ \\
\hline
\end{tabular}

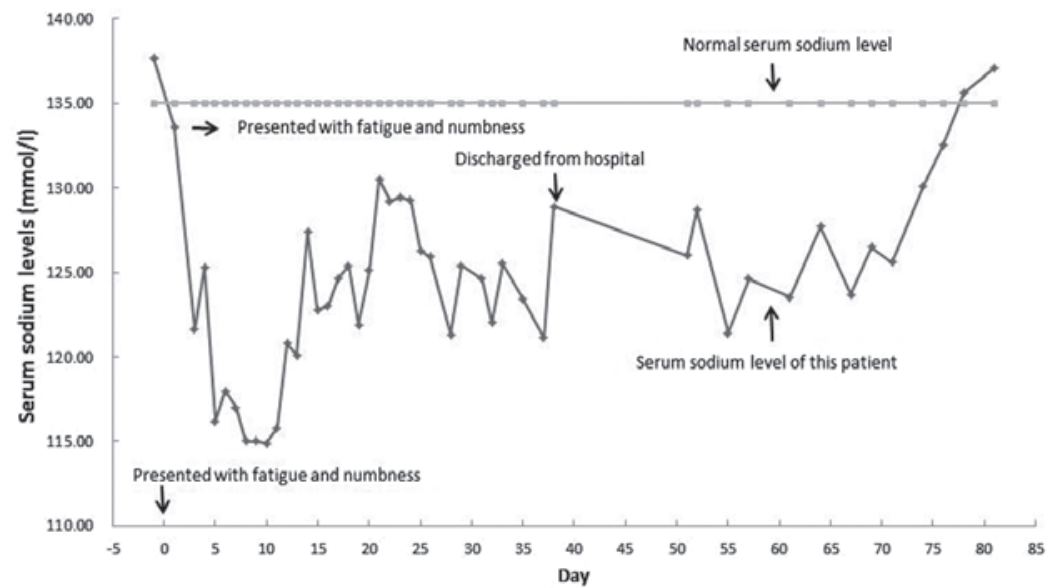

Figure 2. Change of serum sodium levels in this case.

causes, including central nervous system disorders, pulmonary abnormalities and idiopathic forms through collectively analyzing the patient's symptoms, physical examination and tests, a medication side effect was deemed the most probable 
Table III. Frequency of severe hyponatremia in patients treated with bortezomib as reported in previous studies.

\begin{tabular}{lcc}
\hline Authors & $\begin{array}{c}\text { Frequency, \% } \\
\text { (adverse event/total number) }\end{array}$ & (Refs.) \\
\hline Richardson et al & Undetailed & $(3)$ \\
Belch et al & $3.3(1 / 30)$ & $(4)$ \\
O'Connor et al & $12.5(3 / 24)$ & $(5)$ \\
Orlowski et al & $25.9(7 / 27)$ & $(6)$ \\
Van Waes et al & $11(1 / 9)$ & $(7)$ \\
Jagannath et al & $9.2(5 / 54)$ & $(8)$ \\
Richardson et al & $2.6(1 / 38)$ & $(17)$ \\
Davies et al & $3.8(1 / 26)$ & $(18)$ \\
\hline
\end{tabular}

cause. The only medication that was co-administered was dexamethasone. However, glucocorticoids have never been previously associated with SIADH, so it was highly unlikely that dexamethasone was the cause of the electrolyte disorder. Therefore, bortezomib was suspected to be the cause of SIADH in this patient.

Bortezomib was approved for the treatment of patients with multiple myeloma in 2003 by the U.S. Food and Drug Administration. Bortezomib inhibits the proteolytic activity of the proteasome complex in mammalian cells. This inhibition of the intracellular protein degradation pathway alters the levels of several intracellular regulatory and signaling proteins, effectively altering downstream cellular processes in a manner that leads to apoptosis or growth arrest $(15,16)$. Numerous studies have demonstrated the promising effect of bortezomib in treating patients with progressive multiple myeloma. Bortezomib also has a significantly more tolerable side effect profile compared with other traditional chemotherapeutic agents for multiple myeloma.

Bortezomib has been reported to have a wide-ranging side effect profile affecting a number of systems (1). However, the endocrine system is seldom affected in patients receiving bortezomib (2-8), although severe hyponatremia has been reported in $2.6-25.9 \%$ of such patients (Table III) $(3-8,17,18)$.

When patients experience hyponatremia, the symptoms are associated with the severity of the hyponatremia and the duration of time over which the serum sodium level decreased (19). Sudden-onset $(<48 \mathrm{~h})$ and severe hyponatremia may cause emergent, life-threatening symptoms and manifest as seizures, coma, or signs of brain herniation. By contrast, patients with chronic hyponatremia (onset $>48 \mathrm{~h}$ ) may display minimal neurological manifestations. Some patients with long-standing hyponatremia may even be asymptomatic, even in the presence of dangerously low serum sodium levels. The patient in this case study presented with progressive fatigue and numbness of the distal of arms and legs, accompanied by mild hypesthesia and muscle weakness $<$ grade 5 . The patient exhibited a mildly decreased serum sodium level, but the serum sodium level was normal 2 days prior. After treating the patient with oral hypertonic saline for 2 days, the serum sodium level decreased further $(114.9 \mathrm{mmol} / \mathrm{l})$. Despite the patient's very low sodium levels, his symptoms were not severe symptoms. This is likely due to the 4-day interval ( $>48 \mathrm{~h}$ ) over which his serum sodium decreased from normal $(137.7 \mathrm{mmol} / \mathrm{l})$ to severely low $(121.6 \mathrm{mmol} / \mathrm{l})$.

Fluid restriction is considered to be the first-line therapy in SIADH patients, with an initial fluid intake reduction to $800-1,200 \mathrm{ml} / 24 \mathrm{~h} \mathrm{(20)}$. This volume of fluid intake is $500 \mathrm{ml} / 24 \mathrm{~h}$ below the average daily urine volume (21). To prevent a further reduction of serum sodium levels, hypertonic saline $(3 \% \mathrm{NaCl})$ may be infused. The osmolality of hypertonic saline exceeds the osmolality of the urine. Isotonic saline should be avoided, as it may worsen hyponatremia (22). Vaptans, such as tolvaptan, lixivaptan, satavaptan and conivaptan, are $\mathrm{V}_{2}$-receptor vasopressin antagonists and are a promising alternative treatment for hyponatremia. Vaptans counteract the binding of antidiuretic hormone to $\mathrm{V}_{2}$ receptors and promote solute-free water excretion by the kidneys, decrease sodium excretion, further increasing the serum sodium levels (23). The patient in this case report was first treated with hypertonic saline infusion and fluid restriction. While the serum sodium level increased, it never exceeded $131 \mathrm{mmol} / \mathrm{l}$ throughout the duration of his hospital stay (Fig. 2). Vaptans were considered for further treatment to accelerate serum sodium normalization, but were unavailable at the treating hospital and, per hospital policy, could not be obtained from elsewhere. Approximately 80 days after the initial presentation, the patient's serum sodium had normalized $(135 \mathrm{mmol} / \mathrm{l})$ and remained normal throughout the duration of the follow-up period. Bortezomib was permanently discontinued.

In conclusion, treatment with bortezomib is an effective approach for multiple myeloma, but may have side effects on a number of systems, although the endocrine system is infrequently affected. The symptoms of SIADH are non-specific, including fatigue, numbness, coma and seizures, and may be misinterpreted as symptoms of a neurological disorder. Consequently, the diagnosis of SIADH may often be missed, delayed, or misdiagnosed. We herein provide evidence that supports bortezomib as a possible cause of SIADH. Physicians treating patients taking bortezomib who start to feel fatigue, numbness and other neurological symptoms should consider SIADH in the differential diagnosis and consider fluid restriction and infusion of hypertonic saline as treatment options. The patient consented to the publication of this case and associated details.

\section{Acknowledgements}

The authors wish to sincerely thank all the colleagues from the Hematology Department of the Affiliated Drum Tower Hospital of Nanjing University Medical School.

\section{References}

1. Kane RC, Bross PF, Farrell AT and Pazdur R: Velcade: U.S. FDA approval for the treatment of multiple myeloma progressing on prior therapy. Oncologist 8: 508-513, 2003.

2. Brodmann S, GyrKlaas E, Cathomas R, Girardi V and von Moos R: Severe hyponatremia in a patient with mantle cell lymphoma treated with bortezomib. A case report and review of the literature. Onkologie 30: 651-654, 2007.

3. Richardson PG, Sonneveld P, Schuster MW, Irwin D, Stadtmauer EA, Facon T, Harousseau JL, Ben-Yehuda D, Lonial S, Goldschmidt H, et al: Bortezomib or high-dose dexamethasone for relapsed multiple myeloma. N Engl J Med 352: 2487-2498, 2005. 
4. Belch A, Kouroukis CT, Crump M, Sehn L, Gascoyne RD, Klasa R, Powers J, Wright J and Eisenhauer EA: A phase II study of bortezomib in mantle cell lymphoma: The National cancer institute of Canada clinical trials group trial IND.150. Ann Oncol 18: 116-121, 2007.

5. O'Connor OA, Wright J, Moskowitz C, Muzzy J, MacGregor-Cortelli B, Stubblefield M, Straus D, Portlock C, Hamlin P, Choi E, et al: Phase II clinical experience with the novel proteasome inhibitor bortezomib in patients with indolent non-Hodgkin's lymphoma and mantle cell lymphoma. J Clin Oncol 23: 676-684, 2005.

6. Orlowski RZ, Stinchcombe TE, Mitchell BS, Shea TC, Baldwin AS, Stahl S, Adams J, Esseltine DL, Elliott PJ, Pien CS, et al: Phase I trial of the proteasome inhibitor PS-341 in patients with refractory hematologic malignancies. J ClinOncol 20: 4420-4427, 2002.

7. Van Waes C, Chang AA, Lebowitz PF, Druzgal CH, Chen Z, Elsayed YA, Sunwoo JB, Rudy SF, Morris JC, Mitchell JB, et al: Inhibition of nuclear factor-kappaB and target genes during combined therapy with proteasome inhibitor bortezomib and reirradiation in patients with recurrent head-and-neck squamous cell carcinoma. Int J Radiat Oncol Biol Phys 63: 1400-1412, 2005

8. Jagannath S, Barlogie B, Berenson J, Siegel D, Irwin D, Richardson PG, Niesvizky R, Alexanian R, Limentani SA, Alsina M, et al: A phase 2 study of two doses of bortezomib in relapsed or refractory myeloma. Br J Haematol 127: 165-172, 2004

9. Schwartz WB, Bennett W, Curelop S and Bartter FC: Syndrome of renal sodium loss and hyponatremia probably resulting from inappropriate secretion of antidiuretic hormone. Am J Med 23: 529-542, 1957.

10. Ellison DH and Berl T: The syndrome of inappropriate antidiuresis. N Engl J Med 356: 2064-2072, 2007.

11. Waikar SS, Mount DB and Curhan GC: Mortality after hospitalization with mild, moderate, and severe hyponatremia. Am J Med 122: 857-865, 2009

12. Wald R, Jaber BL, Price LL, Upadhyay A and Madias NE: Impact of hospital-associated hyponatremia on selected outcomes. Arch Intern Med 170: 294-302, 2010.
13. Verbalis JG, Barsony J, Sugimura Y, Tian Y, Adams DJ, Carter EA and Resnick HE: Hyponatremia-induced osteoporosis. J Bone Miner Res 25: 554-563, 2010.

14. Kinsella S, Moran S, Sullivan MO, Molloy MG and Eustace JA: Hyponatremia independent of osteoporosis is associated with fracture occurrence. Clin J Am Soc Nephrol 5: 275-280, 2010.

15. Gillessen S, Groettup M and Cerny T: The proteasome, a new target for cancer therapy. Onkologie 25: 534-539, 2002.

16. Ludwig H, Khayat D, Giaccone G and Facon T: Proteasome inhibition and its clinical prospects in the treatment of hematologic and solid malignancies. Cancer 104: 1794-1807, 2005.

17. Richardson PG, Weller E, Jagannath S, Avigon DE, Alsina M, Schlossman RL, Mazumder A, Munshi NC, Ghobrial IM, Doss D, et al: Multicenter, phase I, dose-escalation trial of lenalidomide plus bortezomib for relapsed and relapsed/refractory multiple myeloma. J Clin Oncol 27: 5713-5719, 2009.

18. Davies AM, Ruel C, Lara PN, Lau DH, Gumerlock PH, Bold R, Shibata S, Lenz HJ, Schenkein DP and Gandara DR: The proteasome inhibitor bortezomib in combination with gemcitabine and carboplatin in advanced non-small cell lung cancer: A California cancer consortium phase I study. J Thorac Oncol 3: 68-74, 2008.

19. Reynolds RM and Seckl JR: Hyponatraemia for the clinical endocrinologists. Clin Endocrinol (Oxf) 63: 366-374, 2005.

20. Sherlock $M$ and Thompson CJ: The syndrome of inappropriate antidiuretic hormone: Current and future management options. Eur J Endocrinol 162 (Suppl 1): S13-S18, 2010.

21. Robertson GL, Posterior pituitary. In: Felig P, Baxter JD, Broadus AE and Frohman LA (eds): Endocrinology and Metabolism. 1st edition. New York, McGraw-Hill, pp338-385, 1986.

22. Palmer BF: Hyponatremia in patients with central nervous system disease: SIADH versus CSW. Trends Endocrinol Metab 14: 182-187, 2003.

23. Martin PY, Abraham WT, Lieming X, Olson BR, Oren RM, Ohara M and Schrier RW: Selective V2-receptor vasopressin antagonism decreases urinary aquaporin-2 excretion in patients with chronic heart failure. J Am Soc Nephrol 10: 2165-2170, 1999. 